\title{
A molecular and staging model predicts survival in patients with resected non-small cell lung cancer
}

\author{
Lei Liu ${ }^{1,2}$, Minxin Shi ${ }^{2}$, Zhiwei Wang ${ }^{3}$, Haimin Lu², Chang Li ${ }^{1}$, Yu Tao ${ }^{4}$, Xiaoyan $\mathrm{Chen}^{5}$ and Jun Zhao ${ }^{1^{*}}$ (D)
}

\begin{abstract}
Background: The current TNM staging system is far from perfect in predicting the survival of individual non-small cell lung cancer (NSCLC) patients. In this study, we aim to combine clinical variables and molecular biomarkers to develop a prognostic model for patients with NSCLC.

Methods: Candidate molecular biomarkers were extracted from the Gene Expression Omnibus (GEO), and Cox regression analysis was performed to determine significant prognostic factors. The survival prediction model was constructed based on multivariable Cox regression analysis in a cohort of 152 NSCLC patients. The predictive performance of the model was assessed by the Area under the Receiver Operating Characteristic Curve (AUC) and Kaplan-Meier survival analysis.

Results: The survival prediction model consisting of two genes (TPX2 and MMP12) and two clinicopathological factors (tumor stage and grade) was developed. The patients could be divided into either high-risk group or low-risk group. Both disease-free survival and overall survival were significantly different among the diverse groups $(P<0.05)$. The AUC of the prognostic model was higher than that of the TNM staging system for predicting survival.

Conclusions: We developed a novel prognostic model which can accurately predict outcomes for patients with NSCLC after surgery.
\end{abstract}

Keywords: Non-small cell lung cancer, Survival, TPX2, MMP12

\section{Background}

Lung cancer is one of the most common cancers and its death rate ranks among the top of the all tumors worldwide [1]. Almost $80 \%$ of all lung cancer deaths were non-small cell lung cancer (NSCLC). The overall survival of NSCLC remains poor, although there are tremendous developments of treatments [2]. Tumor-node-metastasis (TNM) system is widely used to estimate the outcome of patients with NSCLC in current clinical practice. However, a completely different prognosis may occur in patients with the same TNM stage [3] .Other traditional clinicopathologic factors including age, sex, pathological type and tumor grade have been reported to correlate to the prognosis of NSCLC [4]. Moreover, it is also believed

\footnotetext{
* Correspondence: Doczhaoj@126.com

${ }^{1}$ Department of Thoracic and Cardiovascular Surgery, The First Affiliated Hospital of Soochow University, Medical College of Soochow University, Suzhou, Jiangsu Province, China

Full list of author information is available at the end of the article
}

that tremendous heterogeneity between patients exists in the biology underlying NSCLC. Therefore, the ideal staging system would join the biology and molecular features of each individual tumor, and correlate prognosis with patient-specific tumor biomarkers.

Recently, the microarray technique which can investigate gene expression systematically enabled us to visualize gene expression profiles in human cancers. People used more and more gene expression to predict the prognosis in different type of tumors [5-8]. For instance, Cao et al. proposed a molecular model based on three genes which could accurately predict the survival of patients of esophageal squamous cell carcinoma [9]. A subnetwork constructed by five signatures could be applied to divide the colorectal cancer patients into high or low risk group [10]. Differences in survival were found between lung cancer patients with and without DNA alterations in genes encoding the metabolism proteome [11]. A predictive 
7-gene assay and prognostic protein biomarkers were established for improving NSCLC treatment. These findings could divide cancer patients into high or low risk group [12]. However, these authors did not use clinical and pathological information in their studies. In the present study, we investigated the prognostic value of the traditional clinicopathological factors and selected protein expression. We aimed to build a novel predictive model, which would be capable of predicting outcomes of NSCLC patients after surgery.

\section{Methods}

\section{Microarray data analysis}

We obtained the microarray data from the publicly available Gene Expression Omnibus databases (GSE 31552 and GSE 18842) in this study. R/BioConductor was used for preprocessing the microarray text data from BeadStudio. The expression level of each gene was transformed into a $\log 2$ base before further analysis. Then, we calculated the $\log 2$ fold change (FC) of each probe on the array within each tissue pair. The differential expression between tumor tissue and matched normal mucosa was tested using rank product test. The differential expression was declared significant if the adjusted $p$-value, i.e. the FDR q-value, was less than 0.05 .

\section{Study patients}

A total of 152 NSCLC patients undergoing curative resection at Nantong tumor hospital between 2011 and 2012 were enrolled in the study. We followed up all the patients using a standard protocol after being discharged from the hospital. The follow-up was carried out until the end of July 2017. The disease free survival was defined as the interval from the date of surgery to the date of local or regional disease recurrence, distant metastasis, or to the last follow-up date. The overall survival was calculated from the time of surgery to the time of death for any cause, or to the time of last follow-up. All the cases were diagnosed as NSCLC by the pathologists. We retrieved patients' clinical information, sex, age, pathological type, and TNM stage (using the 8th UICC TNM Staging System of NSCLC) from their medical records. The clinicopathological characteristics for the patients were listed in Table 1 . This study was approved by the institutional review boards of Nantong tumor hospital. A written informed consent was obtained from each patient.

\section{Real-time quantitative reverse transcription PCR}

A total of $1 \mu \mathrm{g}$ mRNA from each sample was reversely transcribed to single stranded cDNA, using an Advantage RT for PCR kit (Clontech). We used SYBR Green reagent (Applied Biosystems, CA, USA) to analyze mRNA expression for qRT-PCR. The PCR reactions were performed at $95{ }^{\circ} \mathrm{C}$ for five minutes, then a 3 -step cycle procedure was
Table 1 Clinicopathological factors of patients in the study

\begin{tabular}{lll}
\hline Variables & No. & Percent \\
\hline Age (years) & 63 & 41.4 \\
$\quad<60$ & 89 & 58.6 \\
$\geq 60$ & & \\
Gender & 83 & 54.6 \\
Male & 69 & $45.4-$ \\
Female & & \\
Smoking status & 64 & 42.1 \\
Never-smoker & 88 & 57.9 \\
Ever-smoker & & \\
TNM stage & 53 & 34.9 \\
I & 51 & 33.6 \\
II & 48 & 31,5 \\
III & & \\
Grade & 32 & 21.1 \\
Well-differentiated & 64.7 \\
Moderately-differentiated & 66 & 43.4 \\
Poorly-differentiated & 54 & 35.5 \\
Histology & & \\
Squamous cell carcinoma & & \\
Adenocarcinoma & & \\
Postoperative adjuvant therapy & & \\
Yes & & \\
No & & \\
\hline & & \\
\hline
\end{tabular}

performed (denaturation at $95^{\circ} \mathrm{C}$ for $10 \mathrm{~s}$, annealing at $60^{\circ}$ $\mathrm{C}$ for $20 \mathrm{~s}$, and elongation at $72{ }^{\circ} \mathrm{C}$ for $40 \mathrm{~s}$ ) for 35 cycles, with a final extension at $72{ }^{\circ} \mathrm{C}$ for $10 \mathrm{~min}$. GAPDH was served as the endogenous control. The primers used for qRT-PCR analysis were listed in Additional file 2: Table S1. The comparative Ct (threshold cycle) method was used to calculate the relative changes in gene expression.

\section{Immunohistochemical analysis}

We cut the formalin-fixed, paraffin-embedded lung cancer tissues into 4- $\mu \mathrm{m}$ sections and then mounted them on slides. We blocked endogenous peroxidase by incubating the sections in a $0.3 \%$ solution of hydrogen peroxide (in PBS) for $10 \mathrm{~min}$. Then we heated the sections for $10 \mathrm{~min}$ for antigen retrieval at $100{ }^{\circ} \mathrm{C}$ in $10 \mathrm{mM}$ citrate buffer $(\mathrm{pH}$ 6.0). Sections were incubated overnight at $4{ }^{\circ} \mathrm{C}$ with mouse anti-TPX2 (1:200 dilution, ab32795, Abcam, Cambridge, UK) and rabbit anti-MMP12 (1:50 dilution, SC-30072, Santa Cruz, Texas, USA) antibodies. Then, in order to develop peroxidase activity for visualizing the antibody-drochloride complex, the slides were reacted with Novolink polymer followed by DAB chromogen solution. We counterstained all the Slides with haematoxylin. Two pathologists blinded to patients' 
background independently scored the staining of TPX2 and MMP12. We calculated the sum of the percentage and intensity of positively stained invasive tumor cells to perform immunostaining scoring for each sample. The intensity of positive cells was grouped by four grades: 0 , 1, 2 and 3 for negative staining, weak staining, moderate staining and strong staining, respectively. The final staining score was calculated by the following method:score $=$ intensity score $\mathrm{x}$ percentage score $((1 * \% 1+)+(2 * \% 2+)$ $+(3 * \% 3+))$, which ranged from 0 to 300 . The cut off score for protein expression was determined by X-tile [13]. Positive staining was interpreted as score $>40$ for TPX2 and > 50 for MMP12, respectively.

\section{Statistical analysis}

Paired $t$ test was used to compare the mRNA expression in cancer and matched adjacent normal tissues. Cox regression analysis was used to determine the prognostic significance of clinical and pathologic features. The significant prognostic factors in Cox regression analysis were chosen to establish the survival prediction model. To construct a predictive model, each of the selected prognostic factors was analyzed using a multivariable Cox regression model, with DFS or OS as the dependent variable and other clinical information as the covariables. A risk score was then computed as follows: $\mathrm{Y}=\sum_{i=1}^{n}\left(\mathrm{ki}^{*} \mathrm{xi}\right)$,where $\mathrm{Y}$ is the risk score, $\mathrm{N}$ is the number of prognostic factor, $x i$ is the value of prognostic factor, and ki is the estimated regression coefficient of prognostic factor in the multivariable Cox regression analysis. The median risk score was considered as a cut off value. The Kaplan-Meier method was used to estimate the survival of patients in different groups, and the two side log-rank test was applied to determine the statistical significance. Receiver operating characteristic (ROC) curve was used to compare the sensitivity and specificity of the prognostic parameters. All data analysis was performed by using SPSS 15.0 software. The $P$ value less than 0.05 were considered as significant.

\section{Results}

\section{Candidate gene selection}

In GSE18842 dataset, 46 NSCLC samples were included. There were 14 adenocarcinomas and 32 squamous-cell carcinomas cases, respectively; 45 of them were paired with their corresponding nontumor sample. A total of 30 pairs NSCLC and non-tumor samples (10 pairs squamous-cell carcinoma, 18 pairs adenocarcinoma, 2 pairs adeno-squamous carcinoma) were enrolled in GSE31552 dataset. Genes were differentially expressed by comparison of tumor and paired non-tumor samples. Based on adj.P.Val $<0.05$ and $\mid$ Log fold change $\mid>2$, we detected 334 and 1856 genes which showed differentially expression levels in GSE31552 and GSE18842 dataset respectively. Among these genes, 143 up-regulated genes and 123 down-regulated genes were found in both datasets. According to the 20 highest |Log fold change| in two GES datasets, six genes including MMP12, TPX2, DSG3, SFTPC, TMEM100 and AGER were extracted for further analysis.

\section{Gene expression analysis}

Quantitative RT-PCR was carried out to examine whether these six genes were differentially expressed between cancer and normal tissue. The results from 100 tumor and paired normal lung tissue specimens revealed that two of the six genes (TPX2 and MMP12) showed significant expression difference between tumor and normal lung tissue $(P<0.05$,Fig. 1a). However, there was no significant expression difference in other four genes (DSG3, SFTPC, TMEM100 and AGER) $(P>0.05$, Additional file 1: Figure S1). As a result, TPX2 and MMP12 genes were selected to perform further analysis.

\section{Immunohistochemistry for TPX2 and MMP12 expression}

The protein expression of TPX2 and MMP12 was examined by immunohistochemistry in 152 tumor samples. In the carcinoma cells, TPX2 staining was mainly found in the nuclei, while MMP12 expression was mainly observed in the cytoplasm of tumor cells. In these samples, the positive expression rates of TPX2 and MMP12 were up to $48.7 \%$ (74/152) and 58.6\% (89/152), respectively (Fig. 1b).

\section{The construction of survival prediction model}

The median follow-up time for all patients was 31 months (ranged from 3 to 78 months). Univariate Cox analysis showed that TNM stage, tumor grade, postoperative adjuvant therapy, TPX2 expression and MMP12 expression were significantly associated with DFS $(P<0.05)$. Then multivariate Cox proportional hazards regression analysis revealed that TNM stage, tumor grade, TPX2 expression and MMP12 expression were independent predictors $(P<0.05$, Table 2$)$. Our prognostic model for DFS was calculated as:

$$
\begin{aligned}
\mathrm{Y}=3.234 * \mathrm{TNM} & +2.928^{*} \text { Grade }+0.026 * \mathrm{TPX} 2 \\
& +0.025 * \mathrm{MMP} 12 .
\end{aligned}
$$

Patients were ranked and divided into high-risk group $(n=72)$ or low-risk group $(n=80)$ by using median risk score as the cut-off value. As shown in Fig. $2 \mathrm{a}$, the 5 -year DFS rate in high-risk group was significantly lower than that in low-risk group (17.6\%vs $26.2 \%, P=0.025)$. The area under the ROC curve (AUC) value for the survival model was higher than that for TNM system (0.771 (95\%CI, 0.689-0.853) vs 0.719 (95\%CI, 0.633-0.804)) (Fig. 2b).

As for OS, the results of univariate and multivariate Cox analysis were displayed in Table 3. TNM stage, 


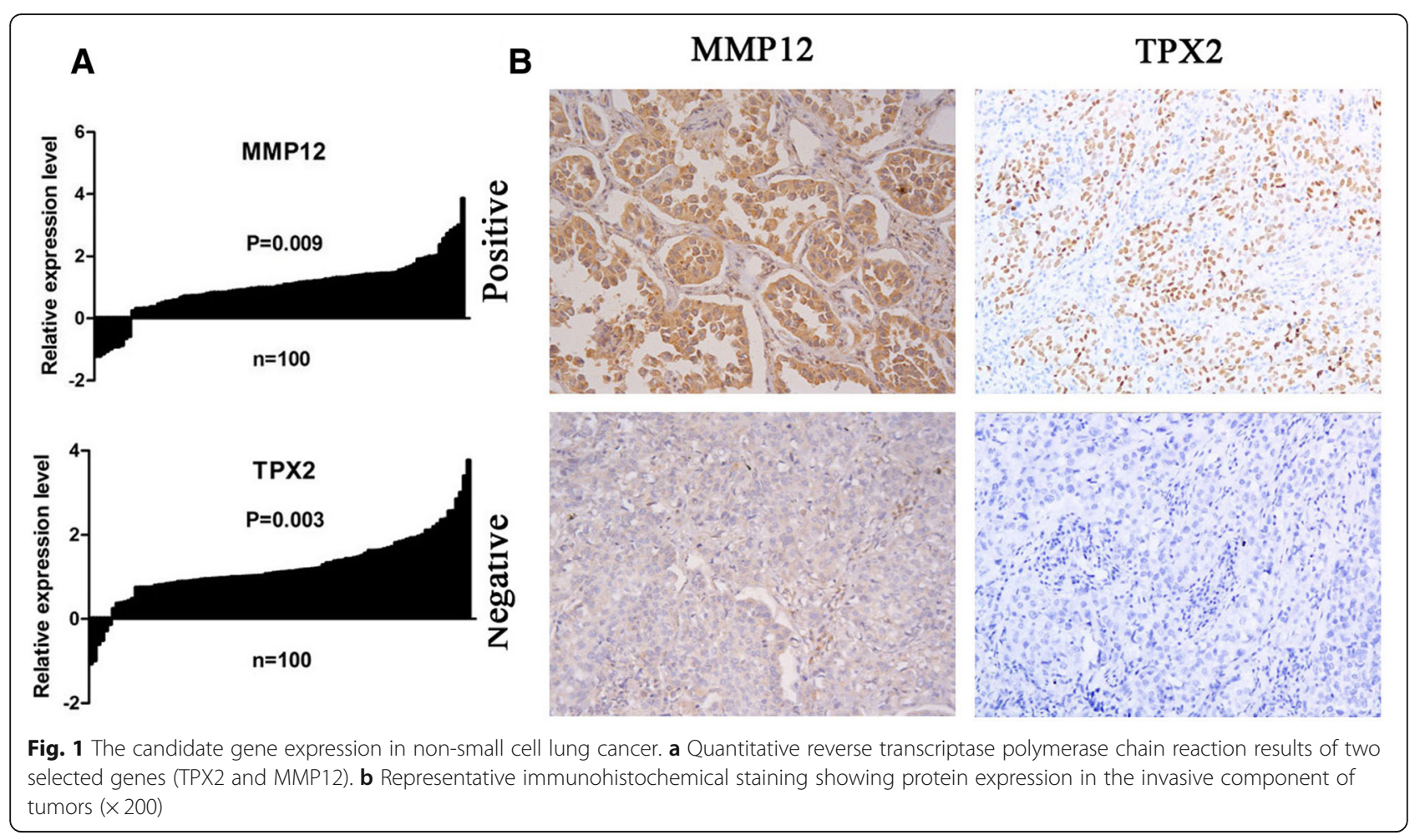

Table 2 Univariate and multivariate Cox proportional hazards regression for disease-free survival

\begin{tabular}{|c|c|c|c|c|c|c|c|}
\hline \multirow[t]{2}{*}{ Variables } & \multirow[t]{2}{*}{ Category } & \multicolumn{3}{|c|}{ Univariate } & \multicolumn{3}{|c|}{ Multivariate } \\
\hline & & $\mathrm{HR}$ & $95 \% \mathrm{Cl}$ & $P$-value & $\mathrm{HR}$ & $95 \% \mathrm{Cl}$ & $P$-value \\
\hline \multirow[t]{2}{*}{ Age (years) } & $<60$ & 1.00 & & & & & \\
\hline & $\geq 60$ & 1.81 & $0.95-3.67$ & 0.089 & & & \\
\hline \multirow[t]{2}{*}{ Gender } & Male & 1.00 & & & & & \\
\hline & Female & 1.04 & $0.83-1.50$ & 0.884 & & & \\
\hline \multirow[t]{2}{*}{ Smoking status } & Never-smoker & 1.00 & & & & & \\
\hline & Ever-smoker & 1.05 & $0.79-1.86$ & 0.913 & & & \\
\hline \multirow[t]{3}{*}{ TNM stage } & 1 & 1.00 & & & 1.00 & & \\
\hline & $\|$ & 1.35 & $1.16-2.48$ & 0.002 & 1.33 & $1.11-2.45$ & 0.003 \\
\hline & III & 2.24 & $1.39-3.59$ & $<0.001$ & 2.32 & $1.45-3.68$ & $<0.001$ \\
\hline \multirow[t]{3}{*}{ Grade } & Well-differentiated & 1.00 & & & 1.00 & & \\
\hline & Moderately-differentiated & 1.24 & $1.10-2.28$ & 0.008 & 1.27 & $1.12-2.40$ & 0.005 \\
\hline & Poorly-differentiated & 1.81 & $1.53-2.92$ & $<0.001$ & 1.85 & $1.55-2.93$ & $<0.001$ \\
\hline \multirow[t]{2}{*}{ Histology } & Squamous cell carcinoma & 1.00 & & & & & \\
\hline & Adenocarcinoma & 0.97 & $0.73-1.48$ & 0.241 & & & \\
\hline \multirow[t]{2}{*}{ Adjuvant therapy } & Yes & 1.00 & & & 1.00 & & \\
\hline & No & 0.90 & $0.80-0.96$ & 0.042 & 0.93 & $0.82-1.04$ & 0.059 \\
\hline \multirow[t]{2}{*}{ TPX2 } & Negative & 1.00 & & & 1.00 & & \\
\hline & Positive & 1.62 & $1.21-2.35$ & $<0.001$ & 1.60 & $1.18-2.31$ & $<0.001$ \\
\hline \multirow[t]{2}{*}{ MMP12 } & Negative & 1.00 & & & 1.00 & & \\
\hline & Positive & 1.76 & $1.32-2.61$ & $<0.001$ & 1.74 & $1.30-2.59$ & $<0.001$ \\
\hline
\end{tabular}



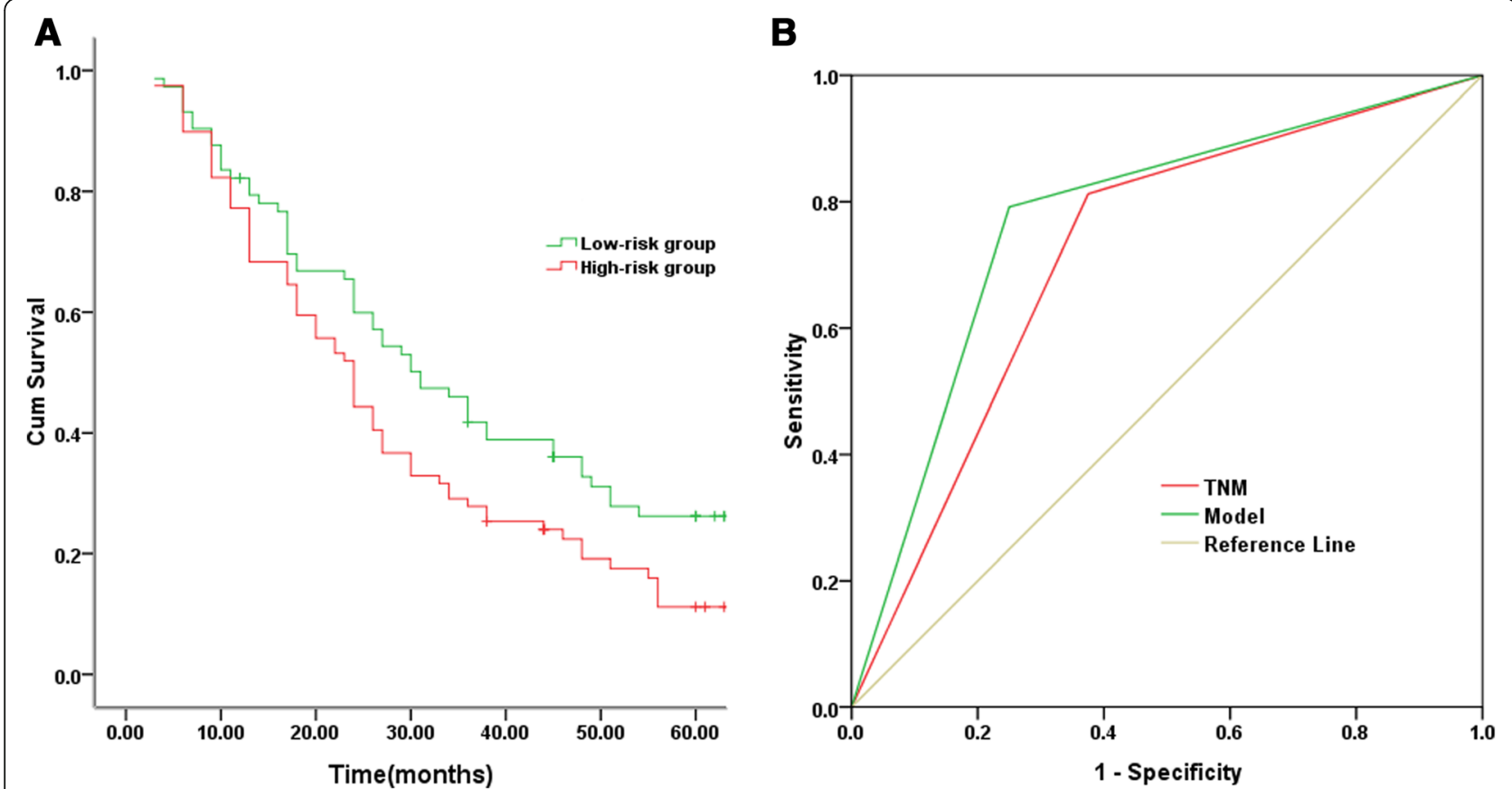

Fig. 2 Disease-free survival prediction by prognostic model. a Differences in survival between subgroups are assessed by log-rank tests. b The predictive ability of the prognostic model as compared with the TNM stage model by ROC curves

Table 3 Univariate and multivariate Cox proportional hazards regression for overall survival

\begin{tabular}{|c|c|c|c|c|c|c|c|}
\hline \multirow[t]{2}{*}{ Variables } & \multirow[t]{2}{*}{ Category } & \multicolumn{3}{|c|}{ Univariate } & \multicolumn{3}{|c|}{ Multivariate } \\
\hline & & $\mathrm{HR}$ & $95 \% \mathrm{Cl}$ & $P$-value & $H R$ & $95 \% \mathrm{Cl}$ & $P$-value \\
\hline \multirow[t]{2}{*}{ Age (years) } & $<60$ & 1.00 & & & & & \\
\hline & $\geq 60$ & 1.25 & $0.96-3.18$ & 0.105 & & & \\
\hline \multirow[t]{2}{*}{ Gender } & Male & 1.00 & & & & & \\
\hline & Female & 1.05 & $0.80-1.43$ & 0.849 & & & \\
\hline \multirow[t]{2}{*}{ Smoking status } & Never-smoker & 1.00 & & & & & \\
\hline & Ever-smoker & 1.03 & $0.84-1.67$ & 0.918 & & & \\
\hline \multirow[t]{3}{*}{ TNM stage } & I & 1.00 & & & 1.00 & & \\
\hline & $\|$ & 1.30 & $1.12-2.39$ & 0.003 & 1.34 & $1.15-2.46$ & 0.001 \\
\hline & III & 2.21 & $1.34-3.49$ & $<0.001$ & 2.28 & $1.42-3.56$ & $<0.001$ \\
\hline \multirow[t]{3}{*}{ Grade } & Well-differentiated & 1.00 & & & 1.00 & & \\
\hline & Moderately-differentiated & 1.23 & $1.90-2.31$ & 0.006 & 1.31 & $1.18-2.43$ & 0.004 \\
\hline & Poorly-differentiated & 1.80 & $1.48-2.95$ & $<0.001$ & 1.81 & $1.47-2.92$ & $<0.001$ \\
\hline \multirow[t]{2}{*}{ Histology } & Squamous cell carcinoma & 1.00 & & & & & \\
\hline & Adenocarcinoma & 0.91 & $0.75-1.38$ & 0.239 & & & \\
\hline \multirow[t]{2}{*}{ Adjuvant therapy } & No & 1.00 & & & 1.00 & & \\
\hline & Yes & 0.89 & $0.77-0.94$ & 0.036 & 0.91 & $0.81-1.03$ & 0.062 \\
\hline \multirow[t]{2}{*}{ TPX2 } & Negative & 1.00 & & & 1.00 & & \\
\hline & Positive & 1.65 & $1.21-2.37$ & $<0.001$ & 1.61 & $1.14-2.26$ & $<0.001$ \\
\hline \multirow[t]{2}{*}{ MMP12 } & Negative & 1.00 & & & 1.00 & & \\
\hline & Positive & 1.72 & $1.30-2.26$ & $<0.001$ & 1.73 & $1.28-2.54$ & $<0.001$ \\
\hline
\end{tabular}


tumor grade, postoperative adjuvant therapy, TPX2 expression and MMP12 expression were all associated with OS $(P<0.05)$. Further multivariate Cox regression analysis showed that TNM stage, tumor grade, TPX2 expression and MMP12 expression were independent prognostic factors $(\mathrm{P}<0.05)$. The predictive model was calculated as described in the equation:

$\mathrm{Y}=3.223 * \mathrm{TNM}+3.114 *$ Grade $+0.030 * \mathrm{TPX} 2$

$$
+0.025^{*} \mathrm{MMP} 12 \text {. }
$$

According to the cut-off value, all patients were divided into either high-risk group $(n=71)$ or low-risk group $(n=81)$. Kaplan-Meier curves showed that patients in high-risk group had a worse outcome than those in low-risk group, and the 5-year OS rates were $21.9 \%$ and $37.7 \%$, respectively $(P=0.021)$ (Fig. 3a). The AUC value of the survival model was larger than that of TNM stage $(0.761 \quad(95 \% \mathrm{CI}, \quad 0.678-0.844)$ vs 0.700 (95\%CI, 0.612-0.787)) (Fig. 3b).

\section{Discussion}

NSCLC clinical outcomes are heterogeneous, and some patients with advanced cancer may have a better prognosis than clinical expectations, and vice versa. At present, the TNM staging system has limited power to predict survival. During the past decades, considerable efforts have been made toward the development of geneexpression-based prognostic biomarkers for NSCLC [14-17]. As a result, well combination of molecular markers and traditional staging system may improve the predictive power. Multivariable analysis in our cohort identified TNM stage and tumor grade as independent prognostic factors (Table 3), which were highly consistent with studies concerning risk factors in NSCLC $[18,19]$. In the present study, we developed a predictive survival model containing clinical stage and two molecular biomarkers for NSCLC. Our predictive model provided more prognostic information than TNM staging system alone. It involved molecular factors which may be found to predict survival except for TNM stage. The predictive power of model was higher than that of clinical stage, with the AUC of 0.771 and 0.761 . NSCLC patients which were predicted to be high-risk had worse outcome and were more prone to experience tumor recurrence or metastasis. These patients were characterized by higher tumor stage and overexpression of TPX2 and MMP12. However, heterogeneity existed within the stageIIgroup. Some patients with stageIIhad good estimated survival. In fact, they were divided into high-risk group by our predictive model and had bad outcomes.Under-treatment caused by traditional standardized therapy regimens could be avoided. Although the AUC value of our model was slightly larger that of TNM stage, it should be pointed that our model cannot supersede TNM staging and should be used in conjunction with TNM stage. Our predictive survival model hence provides a useful and objective adjunct to current staging criteria that incorporates the heterogeneity existing in the biology of NSCLC. Hence, this needs to be kept in mind when interpreting our result.
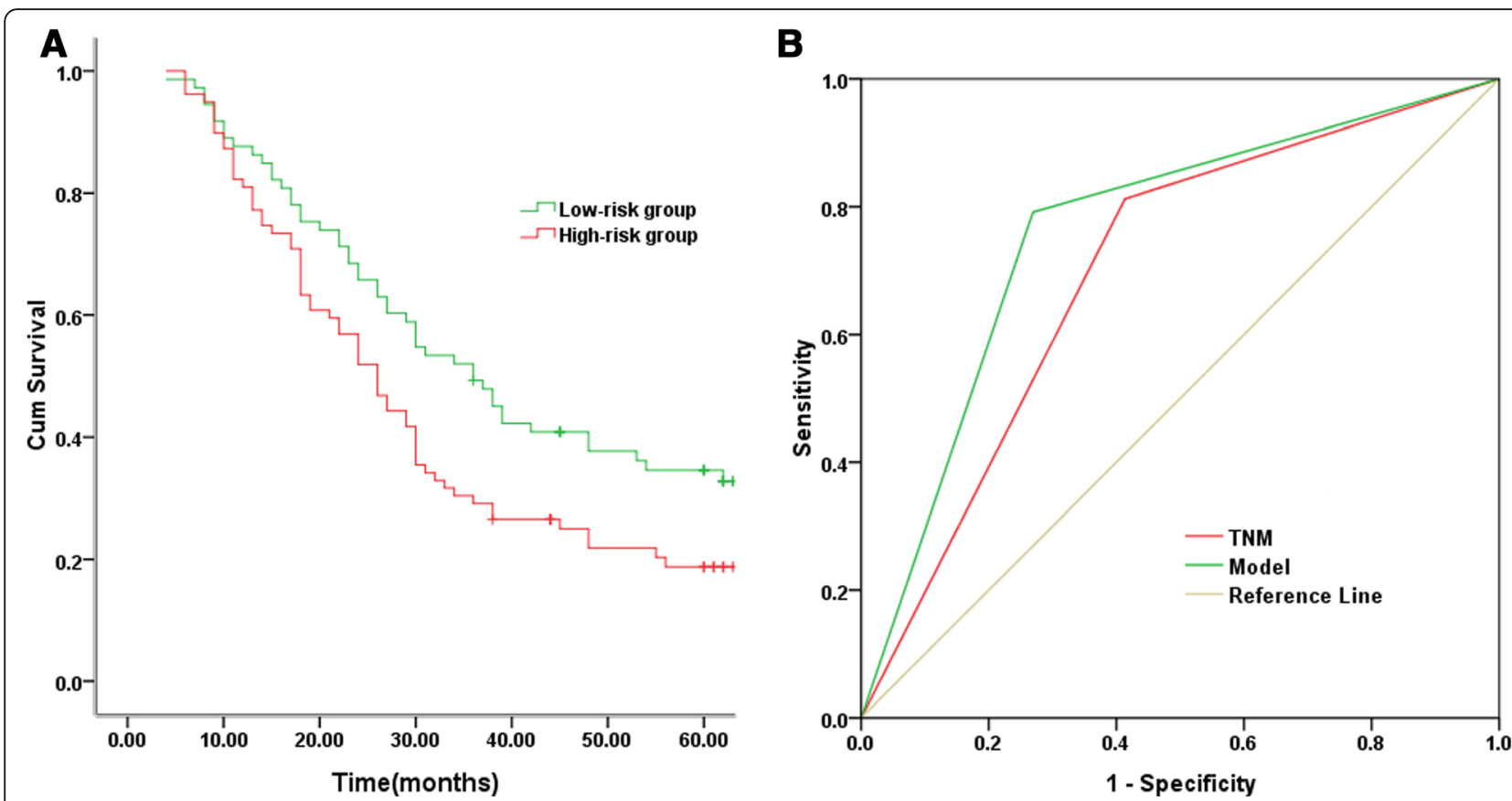

Fig. 3 Overall survival prediction by prognostic model. a Postoperative survival curves of overall survival based on the survival prediction model by the Kaplan-Meier analysis and log-rank test. $\mathbf{b}$ The predictive ability of the prognostic model as compared with the TNM stage model by ROC curves 
MMP12 is one of the metalloproteinases (MMPs), and it causes degradation of the extracellular matrix and basement membranes, and takes part in the pathogenesis of tissue destructive processes in many diseases [20]. Overexpression of MMP12 was observed in various cancers, including gastric cancer, colon cancer and hepatocellular carcinoma [21-23]. And the up-regulation of MMP12 was associated with poor prognosis of cancer [21, 24]. In this study, multivariate Cox regression analysis showed that MMP12 expression was an independent prognostic factor. NSCLC patients with positive expression of MMP12 had a higher Hazard Ratio value for DFS and OS (1.72 (95\%CI,1.30-2.26);1.73(95\%CI1.28-2.54)). Knockdown of MMP12 inhibited proliferation and invasion of lung adenocarcinoma cells followed by the down-regulation of proliferating cell nuclear antigen (PCNA) and vascular endothelial growth factor (VEGF) [25].These results demonstrated that MMP12 played an important role in tumor invasiveness and metastasis.

In human cells, TPX2 which required for microtubule formation is a microtubule-associated protein. In several types of cancers, the overexpression of TPX2 has been reported [26-29]. Moreover, high TPX2 expression was associated with poor survival in gastric cancer and NSCLC $[14,30]$. We also discovered that patients with overexpreeion of TPX2 had a higher Hazard Ratio value for DFS and OS (1.65 (95\%CI,1.21-2.37) and 1.61(95\%CI1.142.26)). Previous studies have revealed that TPX2-siRNA could decrease the viability and proliferation capacity of cancer cell lines [31, 32]. The above observations suggested us that targeted inactivation of TPX2 may have therapeutic benefits.

Previous studies have reported overall-survival predictive model in NSCLC $[15,16]$. In our study, not only overall survival but also disease-free survival were considered as end point. The patients who were at high risk of tumor recurrence or metastasis could get maximal benefit from postoperative adjuvant therapy. In addition, IHC is easy to use in clinical pathology laboratories. However, it should be noted that this study is a retrospective study with limited sample size. Because of the retrospective nature of data collection, the established model failed to enroll some important molecular factors (eg. KRAS mutation and EGFR mutation) [33]. As a result, prospective multicenter study needs to be performed before clinical use.

\section{Conclusion}

In conclusion, our study developed a novel model for predicting the survival of NSCLC patients accurately. These findings could be served as an adjunct to the current clinical risk stratification systems. Our methodology may be useful to both patients and clinical doctors in terms of therapeutic strategies.

\section{Additional files}

Additional file 1: Figure S1. Quantitative reverse transcriptase polymerase chain reaction results of four selected genes. (JPG $135 \mathrm{~kb}$ )

Additional file 2: Table S1. qPCR primers used in this study. (DOC $36 \mathrm{~kb}$ )

\begin{abstract}
Abbreviations
AUC: Area under curve; DFS: Disease free survival; EGFR: Epidermal growth; FDR: False discovery rate; GAPDH: Dlyceraldehyde-3-

phosphatedehydrogenase; GEO: Gene Expression Omnibus; GSE: Gene series; IHC: Immunohistochemistry; KRAS: Kirsten rat sarcoma viral oncogene; MMP12: Matrix metalloproteinase 12; NSCLC: Non-small cell lung cancer; OS: Overall survival; qRT-PCR: Quantitative reverse transcription polymerase chain reaction; ROC: Receiver operating characteristic curve; TNM: Tumornode-metastasis; TPX2: Targeting protein for xklp2
\end{abstract}

\section{Acknowledgments}

We gratefully acknowledge the assistance of Wenjing Wang and Chunxiao Wu from Department of Cancer Control \& Prevention, Shanghai Municipal Center for Disease Control \& Prevention, for their skillful technical assistance.

\section{Funding}

This study was supported in part by funding from Nantong Science and Technology Commission (grant no.:HS149127).

\section{Availability of data and materials}

The datasets generated and analyzed during the current study are not publicly available due to it is a part of Nantong Tumor Hospital database. However, the datasets are available from the corresponding author on reasonable request.

\section{Authors' contributions}

LL, SMX and ZJ were responsible for data collection and analysis, experiment job, interpretation of the results, and writing the manuscript.WZW, LHM,LC, $T Y$ and $C X Y$, were responsible for conducting the data analysis, reviewing and follow-up. LL and ZJ were responsible for experimental design, analysis, and interpretation. All authors have read and approved the final manuscript.

Ethics approval and consent to participate

The study was approved by the institutional review boards of the affiliated tumor hospital of Nantong University (NO.20110012). Informed consent was obtained from all individual participants included in the study.

\section{Consent for publication}

Not applicable.

Competing interests

The authors declare that they have no competing interests.

\section{Publisher's Note}

Springer Nature remains neutral with regard to jurisdictional claims in published maps and institutional affiliations.

\section{Author details}

'Department of Thoracic and Cardiovascular Surgery, The First Affiliated Hospital of Soochow University, Medical College of Soochow University, Suzhou, Jiangsu Province, China. ${ }^{2}$ Department of Thoracic Surgery, The Affiliated Tumor Hospital of Nantong University, Nantong, Jiangsu Province, China. ${ }^{3}$ Department of Breast, International Peace Maternity and Child Health Hospital, Shanghai Jiao Tong University, Shanghai, China. ${ }^{4}$ Department of Pathology, The Affiliated Tumor Hospital of Nantong University, Nantong, Jiangsu Province, China. ${ }^{5}$ Department of Pathology, Shanghai Ruijin Hospital affiliated to Shanghai Jiao Tong University School of Medicine, Shanghai, China. 
Received: 29 January 2018 Accepted: 1 October 2018

Published online: 11 October 2018

\section{References}

1. Torre LA, Bray F, Siegel RL, Ferlay J, Lortet-Tieulent J, Jemal A. Global cancer statistics, 2012. CA Cancer J Clin. 2015;65(2):87-108. https://doi.org/10.3322/ caac.21262.

2. Wang S, Sun T, Sun H, Li X, Li J, Zheng $X$, et al. Survival improvement in patients with non-small cell lung cancer between 1983 and 2012: analysis of the surveillance, epidemiology, and end results database. Tumour Biol. 2017:39(5). https://doi.org/10.1177/1010428317691677.

3. Chansky K, Sculier JP, Crowley JJ, Giroux D, Van Meerbeeck J, Goldstraw P. The International Association for the Study of Lung Cancer staging project: prognostic factors and pathologic TNM stage in surgically managed nonsmall cell lung cancer. J Thorac Oncol 2009;4(7):792-801. doi:https://doi.org/ 10.1097/JTO.0b013e3181a7716e.

4. Sun F, Ma K, Yang X, Li M, Shi Y, Zhan C, et al. A nomogram to predict prognosis after surgery in early stage non-small cell lung cancer in elderly patients. Int J Surg. 2017;42:11-6. https://doi.org/10.1016/j.jjsu.2017.04.024.

5. Ong CA, Shapiro J, Nason KS, Davison JM, Liu X, Ross-Innes C, et al. Threegene immunohistochemical panel adds to clinical staging algorithms to predict prognosis for patients with esophageal adenocarcinoma. J Clin Oncol. 2013;31(12):1576-82. https://doi.org/10.1200/JCO.2012.45.9636.

6. Wang X, Liu Y, Niu Z, Fu R, Jia Y, Zhang L, et al. Prognostic value of a 25 gene assay in patients with gastric cancer after curative resection. Sci Rep. 2017:7(1):7515. https://doi.org/10.1038/s41598-017-07604-y.

7. Kim HS, Umbricht CB, Illei PB, Cimino-Mathews A, Cho S, Chowdhury N, et al. Optimizing the use of gene expression profiling in early-stage breast Cancer. J Clin Oncol. 2016;34(36):4390-7. https://doi.org/10.1200/JCO.2016.67.7195.

8. Sho S, Court CM, Winograd P, Russell MM, Tomlinson JS. A prognostic mutation panel for predicting cancer recurrence in stages II and III colorectal cancer. J Surg Oncol. 2017. https://doi.org/10.1002/jso.24781.

9. Cao HH, Zhang SY, Shen JH, Wu ZY, Wu JY, Wang SH, et al. A three-protein signature and clinical outcome in esophageal squamous cell carcinoma. Oncotarget. 2015;6(7):5435-48. https://doi.org/10.18632/oncotarget.3102

10. Chang W, Gao X, Han Y, Du Y, Liu Q, Wang L, et al. Gene expression profiling-derived immunohistochemistry signature with high prognostic value in colorectal carcinoma. Gut. 2014;63(9):1457-67. https://doi.org/10. 1136/gutjnl-2013-305475.

11. Li L, Wei Y, To C, Zhu CQ, Tong J, Pham NA, et al. Integrated omic analysis of lung cancer reveals metabolism proteome signatures with prognostic impact. Nat Commun. 2014;5:5469. https://doi.org/10.1038/ncomms6469.

12. Guo NL, Dowlati A, Raese RA, Dong C, Chen G, Beer DG, et al. A predictive 7gene assay and prognostic protein biomarkers for non-small cell lung Cancer EBioMedicine. 2018;32:102-10. https://doi.org/10.1016/j.ebiom.2018.05.025.

13. Camp RL, Dolled-Filhart M, Rimm DL. X-tile: a new bio-informatics tool for biomarker assessment and outcome-based cut-point optimization. Clin Cancer Res. 2004;10(21):7252-9. https://doi.org/10.1158/1078-0432.CCR-04-0713.

14. Schneider MA, Christopoulos P, Muley T, Warth A, Klingmueller U, Thomas $M$, et al. AURKA, DLGAP5, TPX2, KIF11 and CKAP5: five specific mitosisassociated genes correlate with poor prognosis for non-small cell lung cancer patients. Int J Oncol. 2017:50(2):365-72. https://doi.org/10.3892/ijo. 2017.3834.

15. Gentles AJ, Bratman SV, Lee LJ, Harris JP, Feng W, Nair RV, et al. Integrating tumor and stromal gene expression signatures with clinical indices for survival stratification of early-stage non-small cell lung Cancer. J Natl Cancer Inst. 2015;107(10). https://doi.org/10.1093/jnci/djv211.

16. Liang W, Zhang L, Jiang G, Wang Q, Liu L, Liu D, et al. Development and validation of a nomogram for predicting survival in patients with resected non-small-cell lung cancer. J Clin Oncol. 2015;33(8):861-9. https://doi.org/10. 1200/JCO.2014.56.6661

17. Mecklenburg I, Sienel W, Schmid S, Passlick B, Kufer P. A threshold of systemic MAGE-A gene expression predicting survival in resected non-small cell lung Cancer. Clin Cancer Res. 2017;23(5):1213-9. https://doi.org/10.1158/ 1078-0432.CCR-16-0557.

18. Wu J, Zhou L, Huang L, Gu J, Li S, Liu B, et al. Nomogram integrating gene expression signatures with clinicopathological features to predict survival in operable NSCLC: a pooled analysis of 2164 patients. J Exp Clin Cancer Res. 2017;36(1):4. https://doi.org/10.1186/s13046-016-0477-x.

19. Zeng $Q$, Xue N, Dai D, Xing S, He X, Li S, et al. A nomogram based on inflammatory factors $C$-reactive protein and fibrinogen to predict the prognostic value in patients with resected non-small cell lung Cancer. J Cancer. 2017:8(5):744-53. https://doi.org/10.7150/jca.17423.

20. Ohbayashi H. Matrix metalloproteinases in lung diseases. Curr Protein Pept Sci. 2002;3(4):409-21.

21. Xu J, E C YY, Ren S, Wang G, Jin H. Matrix metalloproteinase expression and molecular interaction network analysis in gastric cancer. Oncol Lett. 2016; 12(4):2403-8. https://doi.org/10.3892/ol.2016.5013.

22. Klupp F, Neumann L, Kahlert C, Diers J, Halama N, Franz C, et al. Serum MMP7, MMP10 and MMP12 level as negative prognostic markers in colon cancer patients. BMC Cancer. 2016;16:494. https://doi.org/10.1186/s12885016-2515-7.

23. Hass HG, Vogel U, Scheurlen M, Jobst J. Gene-expression analysis identifies specific patterns of dysregulated molecular pathways and genetic subgroups of human hepatocellular carcinoma. Anticancer Res. 2016;36(10): 5087-95. https://doi.org/10.21873/anticanres.11078.

24. Ng KT, Qi X, Kong KL, Cheung BY, Lo CM, Poon RT, et al. Overexpression of matrix metalloproteinase-12 (MMP-12) correlates with poor prognosis of hepatocellular carcinoma. Eur J Cancer. 2011;47(15):2299-305. https://doi. org/10.1016/j.ejca.2011.05.032.

25. LV FZ, Wang JL, Wu Y, Chen HF, Shen XY. Knockdown of MMP12 inhibits the growth and invasion of lung adenocarcinoma cells. Int J Immunopathol Pharmacol. 2015:28(1):77-84. https://doi.org/10.1177/0394632015572557.

26. Glaser ZA, Love HD, Guo S, Gellert L, Chang SS, Herrell SD, et al. TPX2 as a prognostic indicator and potential therapeutic target in clear cell renal cell carcinoma. Urol Oncol. 2017;35(5):286-93. https://doi.org/10.1016/j.urolonc. 2016.12.012.

27. Caceres-Gorriti KY, Carmona E, Barres V, Rahimi K, Letourneau IJ, Tonin PN, et al. RAN nucleo-cytoplasmic transport and mitotic spindle assembly partners XPO7 and TPX2 are new prognostic biomarkers in serous epithelial ovarian cancer. PLoS One. 2014;9(3):e91000. https://doi.org/10.1371/journal. pone.0091000

28. Hsu PK, Chen HY, Yeh YC, Yen CC, Wu YC, Hsu CP, et al. TPX2 expression is associated with cell proliferation and patient outcome in esophageal squamous cell carcinoma. J Gastroenterol. 2014;49(8):1231-40. https://doi. org/10.1007/s00535-013-0870-6.

29. Huang Y, Guo W, Kan H. TPX2 is a prognostic marker and contributes to growth and metastasis of human hepatocellular carcinoma. Int J Mol Sci. 2014;15(10):18148-61. https://doi.org/10.3390/ijms151018148.

30. Tomii C, Inokuchi M, Takagi Y, Ishikawa T, Otsuki S, Uetake H, et al. TPX2 expression is associated with poor survival in gastric cancer. World J Surg Oncol. 2017;15(1):14. https://doi.org/10.1186/s12957-016-1095-y.

31. Wei $P$, Zhang $N, X u Y$, Li X, Shi D, Wang $Y$, et al. TPX2 is a novel prognostic marker for the growth and metastasis of colon cancer. J Transl Med. 2013; 11:313. https://doi.org/10.1186/1479-5876-11-313.

32. Chang H, Wang J, Tian Y, Xu J, Gou X, Cheng J. The TPX2 gene is a promising diagnostic and therapeutic target for cervical cancer. Oncol Rep. 2012;27(5):1353-9. https://doi.org/10.3892/or.2012.1668.

33. Mencoboni M, Filiberti RA, Taveggia P, Bruzzone A, Garuti A, Del Corso L, et al. Outcome of EGFR inhibitors treatment in advanced NSCLC patients, not enrolled in clinical trials. Neoplasma. 2017;64(2):253-61. https://doi.org/ 10.4149/neo_2017_212.

\section{Ready to submit your research? Choose BMC and benefit from:}

- fast, convenient online submission

- thorough peer review by experienced researchers in your field

- rapid publication on acceptance

- support for research data, including large and complex data types

- gold Open Access which fosters wider collaboration and increased citations

- maximum visibility for your research: over $100 \mathrm{M}$ website views per year

At $\mathrm{BMC}$, research is always in progress.

Learn more biomedcentral.com/submission 